\title{
MARCADORES MICROSSATÉLITES PARA CARACTERIZAÇÃO GENÉTICA DE CAPRINOS DA RAÇA SAANEN NA REGIÃO SUL DO ESTADO DO ESPÍRITO SANTO - BRASIL
}

\footnotetext{
Bárbara de Cássia Ribeiro Vieira ${ }^{1}$, Marcela Brite Alfaiate ${ }^{2}$, Ana Paula Guedes Oliveira $^{1}$, Mayk Henrique Souza ${ }^{3}$, João Batista Esteves Peluzio ${ }^{4}$

${ }^{1}$ Mestrandas em Ciências Veterinárias pelo Programa de Pós graduação em Ciências Veterinárias da Universidade Federal do Espírito Santo, Campus de Alegre, Alto Universitário, s/no, Guararema - 29500-000, Alegre - ES, Brasil. email:barbaravieira.biologia@gmail.com.

${ }^{2}$ Graduanda em Bacharelado em Ciências Biológicas pelo Instituto Federal de Educação Ciência e Tecnologia do Espírito Santo, Campus de Alegre, Rua Principal, s/n, Distrito de Rive - CEP: 29500-000, Alegre - ES, Brasil.

${ }^{3}$ Pós-graduando em Agroecologia pelo Instituto Federal de Educação Ciência e Tecnologia do Espírito Santo, Campus de Alegre, Alegre - ES, Brasil.

${ }^{4}$ Professor do Instituto Federal de Educação Ciência e Tecnologia do Espírito Santo, Campus de Alegre, Alegre - ES, Brasil.
}

Recebido em: 08/09/2015 - Aprovado em: 14/11/2015 - Publicado em: 01/12/2015 DOI: http://dx.doi.org/10.18677/Enciclopedia_Biosfera_2015_191

\begin{abstract}
RESUMO
Objetivou-se utilizar marcadores microssatélites para caracterizar geneticamente os caprinos da raça Saanen da região sul do estado do Espírito Santo. O protocolo de extração de DNA utilizado nos bulbos pilosos foi o protocolo de lise, onde os materiais resultantes deste foram submetidos à amplificação via PCR. Foram testados trinta e um iniciadores com diferentes gradientes de temperatura. Os produtos finais da PCR foram submetidos à eletroforese, revelados e visualizados com auxílio de fotodocumentador. O protocolo de lise utilizado para extração do DNA foi eficiente. Contudo não houve amplificação de nenhum marcador microssatélite, indicando a não eficiência dos diferentes gradientes de temperatura testados, bem como, quanto aos iniciadores utilizados, sendo necessária nova triagem. Conclui-se que o protocolo para extração foi eficiente para a espécie em questão, necessitando-se ainda, de uma nova triagem dos iniciadores microssatélites.
\end{abstract}

PALAVRAS-CHAVE: Capra hircus, diversidade genética, marcador molecular, variabilidade genética

\section{MARKERS MICROSATELLITE TO GENETIC CHARACTERIZATION OF THE GOATS OF BREED SAANEN IN THE SOUTH REGION OF STATE ESPÍRITO SANTO - BRAZIL}

\begin{abstract}
The objective of this study was to use microsatellite markers to characterize genetically the goats of breed Saanen in the south region of state Espírito Santo Brazil. The DNA extraction protocol used in hair bulbs was the lysis protocol, where the materials resulting from this were submitted to amplification by PCR. Thirty-one primers with different temperature gradients were tested. The end products of the
\end{abstract}


PCR were subjected to electrophoresis and revealed, and the possible visualization of the amplified microsatellite was performed via high-resolution gel imaging system.The lysis protocol used for DNA extraction was efficient, but there was no amplification of any microsatellite marker, indicating the not efficiency of the different temperature gradients tested, as well, the primers used. It is concluded that the protocol used for extracting was efficient of DNA for the species in question, necessitating further of new studies with markers microsatellite.

KEYWORDS: Capra hircus, genetic diversity, molecular marker, genetic variability

\section{INTRODUÇÃO}

A caprinocultura é uma atividade de grande importância econômica e social no Brasil (SILVESTRE et al., 2015) e no mundo, devido a produção de leite e de corte, tornando os caprinos um dos principais animais de produção (SILVA et al., 2014a), havendo um crescente aumento quanto ao número de rebanhos e produtividade dos mesmos (LOPES et al., 2012).

Encontram-se amplamente distribuídos pelo território nacional, destacadamente no Nordeste, região de maior produção e que reúne condições ambientais e socioeconômicas próprias. Estima-se que o efetivo rebanho caprino brasileiro seja da ordem de 14 milhões de animais, distribuídos em 436 mil estabelecimentos agropecuários (MAPA, 2014).

No estado do Espírito Santo, os caprinos são contabilizados em 17. 743 animais (IBGE, 2013) contribuindo de forma significativa no que diz respeito a segurança alimentar e sobrevivência da família rural (MADELLA-OLIVEIRA \& QUIRINO, 2012).

Esses pequenos ruminantes fornecem proteína animal e renda para a população dependente da pecuária, sendo manejados de forma extensiva e sem controle zootécnico (MADELLA-OLIVEIRA \& QUIRINO, 2012), além de segundo SILVA et al. (2014a) faltar a manutenção dos registros dos animais. Ressalta-se que a falta de acompanhamento técnico pode acarretar aumento da homozigose, e consequentemente, ocorrência de mutações nas gerações futuras, além do risco de morte dos nascituros, havendo elevados prejuízos.

A biologia molecular tem contribuído significativamente nos estudos genéticos de diversas espécies (ABAD et al., 2014). Tal ferramenta faz uso de marcadores moleculares, os quais, segundo FERREIRA \& GRATTAPAGLIA (1998) são considerados etiquetas desenhadas a partir de regiões polimórficas, podendo ser provenientes, conforme CURI (2000), de polimorfismos resultantes de deleções, substituições e adições de bases nitrogenadas no genoma.

Dentre os diversos tipos de marcadores moleculares, destacam-se os microssatélites, compostos por sequências simples, ao acaso, repetidas no genoma em "tandem" (MENEZES et al., 2006). As repetições ocorrem de 5 a 20 vezes (GOLDSTEIN \& SCHÖTTERER, 1999) envolvendo individualmente, 1 a 6 nucleotídeos (BORÉM \& CAIXETA, 2009). São vantajosos por sua codominância (KALIA et al., 2011), por não sofrerem influências ambientais, terem alta reprodutibilidade, exigirem pouca quantidade de DNA para análises das amostras (FERREIRA \& GRATTAPAGLIA, 1998), serem seletivamente neutros, multialélicos (JARNE \& LAGODA, 1996) e de herança mendeliana simples (GOLDSTEIN \& SCHLOTTERER, 1999).

Os microssatélites são ainda utilizados para evidenciação de relações muito próximas entre populações, como os testes de paternidade (KALIA et al., 2011; SILVESTRE et al., 2015), os estudos de variabilidade genética (FERREIRA; 
GRATAPAGLIA, 1998), mapeamento genômico (SANTANA et al., 2012; TEIXEIRA, 2014) conservação das espécies (VIANNA, 2015).

Estudos de diversidade genética caprina por meio do uso de marcadores microssatélites têm sido realizados nos últimos anos no Brasil (MENEZES et al., 2006; ARAÚJO et al., 2010; MACIEL, 2011; LOPES, 2012; SILVESTRE, 2012; SILVESTRE et al., 2015). Contudo, a maioria das pesquisas ainda é realizada com ecótipos nordestinos, o que torna escassas as informações referentes aos rebanhos em outras regiões brasileiras. É importante salientar que a desinformação pode conduzir a perdas genéticas, uma vez, que para BARROS et al. (2011), cada espécie regional representa um patrimônio cultural e biológico únicos.

Assim, no presente trabalho, buscou-se preencher as lacunas quanto à variabilidade genética de caprinos da raça Saanen da região sul do estado do Espírito Santo por meio da utilização de marcadores microssatélites.

\section{MATERIAL E MÉTODOS}

Foram estudados rebanhos de quatro propriedades rurais da região sul do estado do Espírito Santo, envolvendo 179 animais (tabela 1) de variadas raças (Saanen, Togguerburg e Parda Alpina), mestiços e animais sem raça definida (SRD).

TABELA 1. Localização e número de animais das propriedades.

\begin{tabular}{ccc}
\hline Propriedade & Localização & Animais \\
\hline 1 & Rive, distrito de Alegre-ES & 78 \\
2 & Jerônimo Monteiro-ES & 24 \\
3 & Itapemirim-ES & 54 \\
4 & Cachoeiro de Itapemirim-ES & 23 \\
TOTAL & & $\mathbf{1 7 9}$ \\
\hline
\end{tabular}

Devido à importância da raça Saanen como alternativa de produção leiteira na região sul do estado do Espírito Santo (MADELLA-OLIVEIRA \& QUIRINO, 2012), apenas a mesma teve sua variabilidade genética estudada.

A análise molecular foi realizada nos laboratórios de Biologia Molecular e Genética do IFES - Campus de Alegre e da Universidade Estadual do Norte Fluminense Darcy Ribeiro (UENF). Foram analisados todos os animais da raça Saanen, totalizando 131 caprinos. Essa quantidade de indivíduos encontra-se dentro do necessário para estudos desta natureza (HEDRICK, 1999).

O DNA foi coletado, por animal, à partir de amostras de pelos com bulbos pilosos, armazenados em sacos de papel com superfície não encerada com o objetivo de manter a integridade dos bulbos até o momento de sua utilização (SOUZA et al. 2010).

Para cada extração de DNA foram utilizados 10 bulbos de pelos. Cada um dos pelos foi previamente observado ao microscópio óptico no aumento de 40X para a verificação da integridade e presença do bulbo, para posteriormente ser cortado (separando-o do restante do pelo) e colocado em microtubos de 1,5 mililitros.

Para a reação de extração de DNA utilizou-se o protocolo estabelecido por CORRÊA (2013). Foi realizada a triagem de 31 iniciadores, cada um com diferentes gradientes de temperatura (tabela 2) para averiguar a amplificação. De acordo com a Food Agriculture Organization (FAO) recomenda-se, no mínimo, 25 loci de microssatélites para estudos de distância genética das espécies. 
TABELA 2. Iniciadores, gradientes de temperatura e sequências direta e reversa.

\begin{tabular}{|c|c|c|}
\hline Iniciadores & Temperaturas (C) & Sequências direta (D) e reversa (R) \\
\hline CSRD247 & \multirow{2}{*}{$\begin{array}{c}48 ; 48,5,49 ; 49,5 ; 50 \\
50,5 ; 56 ; 61\end{array}$} & $\begin{array}{l}\text { D: GGACTTGCCAGAACTCTGCAAT } \\
\text { R: CACTGTGGTTTGTATTAGTCAGG }\end{array}$ \\
\hline ILSTS011 & & $\begin{array}{l}\text { D: GCTTGCTACATGGAAAGTGC } \\
\text { R: CTAAAATGCAGAGCCCTACC }\end{array}$ \\
\hline BM1818 & \multirow{2}{*}{$56 ; 57 ; 58 ; 59 ; 60 ; 61$} & $\begin{array}{c}\text { D: AGCTGGGAATATAACCAAAGG } \\
\text { R: AGTGCTTTCAAGGTCCATGC }\end{array}$ \\
\hline BM6506 & & $\begin{array}{l}\text { D: GCACGTGGTAAAGAGATGGC } \\
\text { R: AGCAACTTGAGCATGGCAC }\end{array}$ \\
\hline OarFCB304 & $58 ; 5 ; 60 ; 61 ; 61,5 ; 62$ & $\begin{array}{l}\text { D: GAGTTAGTACAAGGATGACAAGAGGCAC } \\
\text { R: CGCTGCTGTCAACTGGGTCAGGG }\end{array}$ \\
\hline MAF65 & \multirow{3}{*}{$55 ; 56 ; 57 ; 58 ; 59 ; 60 ; 61$} & $\begin{array}{l}\text { D: AAAGGCCAGAGTATGCAATTAGGAG } \\
\text { R: CCACTCCTCCTGAGAATATAACATG }\end{array}$ \\
\hline CSSM66 & & $\begin{array}{l}\text { D: ACACAAATCCTTTCTGCCAGCTTGG } \\
\text { R: AATTTAATGCACTGAGGAGCTTGG }\end{array}$ \\
\hline SRCRSP8 & & $\begin{array}{c}\text { D: TGCGGTCTGGTTCTGATTTCAC } \\
\text { R: CCTGCATGAGAAAGTCGATGCTTAG }\end{array}$ \\
\hline HAUT27 & \multirow{4}{*}{$56 ; 57 ; 58 ; 59 ; 60 ; 61$} & $\begin{array}{l}\text { D: TTTTATGTTCATTTTTTGACTGG } \\
\text { R: AACTGCTGAAATCTCCATCTTA }\end{array}$ \\
\hline CSRM60 & & $\begin{array}{l}\text { D: AAGATGTGATCCAAGAGAGAGGCA } \\
\text { R: AGGACCAGATCGTGAAAGGCATAG }\end{array}$ \\
\hline BM6526 & & $\begin{array}{c}\text { D: CATGCCAAACAATATCCAGC } \\
\text { R: TGAAGGTAGAGAGCAAGCAGC }\end{array}$ \\
\hline McM527 & & $\begin{array}{l}\text { D: GTCCATTGCCTCAAATCAATTC } \\
\text { R:AAACCACTTGACTACTCCCCAA }\end{array}$ \\
\hline OarFCB48 & $58 ; 59 ; 60 ; 61,5 ; 62$ & $\begin{array}{c}\text { D:GAGTTAGTACAAGGATGACAAGAGGCAC } \\
\text { R:GACTCTAGAGGATCGCAAAGAACCAG }\end{array}$ \\
\hline INRA06 & $\begin{array}{l}48 ; 49 ; 50 ; 50,5 ; 59,5 ; 60 \\
60,5 ; 61 ; 61,5 ; 62\end{array}$ & $\begin{array}{c}\text { D:AGGAATATCTGTATCAACCTCAGTC } \\
\text { R:CTGAGCTGGGGTGGGAGCTATAAATA }\end{array}$ \\
\hline INRA23 & \multirow{2}{*}{$56 ; 57 ; 58 ; 59 ; 60 ; 60,5$} & $\begin{array}{c}\text { D:GAGTAGAGCTACAAGATAAACTTC } \\
\text { R:TAACTACAGGGTGTTAGATGAACTCA }\end{array}$ \\
\hline INRA63 & & $\begin{array}{l}\text { D:ATTTGCACAAGCTAAATCTAACC } \\
\text { R:AAACCACAGAAATGCTTGGAAG }\end{array}$ \\
\hline HSC & $56 ; 57 ; 58 ; 59 ; 60 ; 61$ & $\begin{array}{c}\text { D:CTGCCAATGCAGAGACACAAGA } \\
\text { R:GTCTGTCTCCTGTCTTGTCATC }\end{array}$ \\
\hline ETH225 & \multirow{3}{*}{$55 ; 56 ; 57 ; 58 ; 59 ; 60 ; 61$} & $\begin{array}{l}\text { D: GATCACCTTGCCACTATTTCCT } \\
\text { R: ACATGACAGCCAGCTGCTACT }\end{array}$ \\
\hline ETH10 & & $\begin{array}{l}\text { D: GTTCAGGACTGGCCCTGCTAACA } \\
\text { R: CCTCCAGCCCACTTTCTCTTCTC }\end{array}$ \\
\hline BM1329 & & $\begin{array}{l}\text { D: TTGTTTAGGCAAGTCCAAAGTC } \\
\text { R: AACACCGCAGCTTCATCC }\end{array}$ \\
\hline OarFCB11 & \multirow{2}{*}{$\begin{array}{c}55 ; 56 ; 57 ; 58 ; 59 ; 60 ; 61 ; \\
61,5\end{array}$} & $\begin{array}{c}\text { D: GGCCTGAACTCACAAGTTGATATATCTATCAC } \\
\text { R: GCAAGCAGGTTCTTTACCACTAGCACC }\end{array}$ \\
\hline INRA05 & & $\begin{array}{l}\text { D: TTCAGGCATACCCTACACCACATG } \\
\text { R: AAATATTAGCCAACTGAAAACTGGG }\end{array}$ \\
\hline TGLA122 & \multirow{4}{*}{$55 ; 56 ; 57 ; 58 ; 59 ; 60 ; 61$} & $\begin{array}{c}\text { D: CCCTCCTCCAGGTAAATCAGC } \\
\text { R: AATCACATGGCAAATAAGTACATAC }\end{array}$ \\
\hline SPS115 & & $\begin{array}{l}\text { D: AAAGTGACACAACAGCTTCTCCAG } \\
\text { R: AACGAGTGTCCTAGTTTGGCTGTG }\end{array}$ \\
\hline BM8125 & & $\begin{array}{l}\text { D: CTCTATCTGTGGAAAAGGTGGG } \\
\text { R: GGGGGTTAGACTTCAACATACG }\end{array}$ \\
\hline MM12 & & $\begin{array}{l}\text { D: CAAGACAGGTGTTTCAATCT } \\
\text { R: ATCGACTCTGGGGATGATGT }\end{array}$ \\
\hline MAF209 & $54 ; 55 ; 56 ; 57 ; 58 ; 59$ & $\begin{array}{l}\text { D: GATCACAAAAAGTTGGATACAACGTGG } \\
\text { R: TCATGCACTTAAGTATGTAGGATGCTG }\end{array}$ \\
\hline ILSTS05 & \multirow{2}{*}{$57 ; 58 ; 59 ; 60 ; 61 ; 62$} & $\begin{array}{c}\text { D: GGAAGCAATGAAATCTATAGCC } \\
\text { R: TGTTCTGTGAGTTTGTAAGC }\end{array}$ \\
\hline MAF65 & & $\begin{array}{l}\text { D: AAAGGCCAGAGTATGCAATTAGGAG } \\
\text { R: CCACTCCTCCTGAGAATATAACATG }\end{array}$ \\
\hline INRA172 & $61 ; 62 ; 63 ; 63,5$ & $\begin{array}{l}\text { D: CCACTTCCCTGTATCCTCCT } \\
\text { R: GGTGCTCCCATTGTGTAGAC }\end{array}$ \\
\hline INRA35 & $54 ; 55 ; 56 ; 57 ; 58 ; 59$ & $\begin{array}{l}\text { D: ATCCTTTGCAGCCTCCACATTG } \\
\text { R: TTGTGCTTTATGACACTATCCG }\end{array}$ \\
\hline
\end{tabular}


As reações de amplificação foram completadas para um volume final de 19 $\mu \mathrm{L}$, contendo os seguintes reagentes: $10 \mathrm{mmol} \mathrm{L}^{-1}$ Tris $\mathrm{HCl}, \mathrm{pH} 8,3 ; 20 \mathrm{mmol} \mathrm{L}^{-1} \mathrm{KCl}$; $2,4 \mathrm{mmol} \mathrm{L}^{-1} \mathrm{MgCl}_{2} ; 100 \mu \mathrm{mol} \mathrm{L}^{-1}$ de cada um dos dNTP; $0,4 \mu \mathrm{mol} \mathrm{L}^{-1}$ de cada um dos iniciadores (forward e reverse); 2,5ng de DNA genômico e; 0,1 unidade de Taq DNA polimerase, completando-se o volume com água ultrapura. Foram aplicadas 2,0 $\mu \mathrm{L}$ de DNA e posteriormente, adicionado o mix descrito anteriormente.

As reações de PCR (GeneAmp PCR System 9700 Thermal cycler - Applied Biosystems) foram conduzidas da seguinte forma: desnaturação (1 min. a $95^{\circ} \mathrm{C}$ ); ciclagem (40 ciclos a $95^{\circ} \mathrm{C}$ por $30 \mathrm{seg}$. seguidos por $1 \mathrm{~min}$. a $48-62^{\circ} \mathrm{C}$, dependendo do iniciador utilizado e $72{ }^{\circ} \mathrm{C}$ por 1 min.) e uma extensão final ( $72^{\circ} \mathrm{C}$ por 7 min.).

A amplificação por PCR foi realizada em gel de poliacrilamida (8\%), o qual foi composto por $8 \mathrm{~mL}$ de acrilamida à $30 \%, 6 \mathrm{~mL}$ de TBE $5 \mathrm{x}, 300 \mathrm{~mL}$ de PSA a $10 \%, 20$ $\mathrm{mL}$ de TEMED e água destilada para completar. $\mathrm{O}$ mesmo continha $20 \mathrm{~cm}$ de largura, com 24 amostras por gel, incluindo dois padrões de pesos moleculares de 25 e $100 \mathrm{pb}$.

Os géis de poliacrilamida foram corados com nitrato de prata. Para a coloração, inicialmente, os géis foram mergulhados em uma solução fixadora (100 $\mathrm{mL}$ de etanol, $5 \mathrm{~mL}$ de ácido acético e $895 \mathrm{~mL}$ de água destilada) por 5 minutos. Posteriormente, foram adicionados $50 \mathrm{~mL}$ de solução de nitrato de prata $(0,2 \mathrm{~g}$ de nitrato de prata e $50 \mathrm{~mL}$ de água destilada) por 10 minutos. As soluções foram descartadas e o gel lavado com água destilada por 2 minutos.

Por fim, os géis foram mergulhados em solução reveladora $(30 \mathrm{~g} \mathrm{NaOH}, 5 \mathrm{~mL}$ de formol e aproximadamente $900 \mathrm{~mL}$ de água) até que as bandas do gel, correspondentes aos fragmentos de DNA amplificados, se tornassem nítidas. Todas as etapas foram executadas com leve agitação com o intuito de promover uma coloração uniforme. Os fragmentos gerados foram submetidos à luz UV para visualização dos resultados (Fotodocumentador Minibis Pro - Bio-imaging System). As imagens dos géis foram capturadas para posterior análise.

\section{RESULTADOS E DISCUSSÃO}

A quantidade de animais de cada raça, animais sem raça definida (SRD) e grupos genéticos (mestiços) encontrados nas propriedades visitadas podem ser visualizada na tabela 3 .

TABELA 3. Quantidade de animais de cada raça, SRD e mestiços encontrados nas propriedades visitadas.

\begin{tabular}{|c|c|c|c|c|c|}
\hline \multirow{2}{*}{ Raças } & \multicolumn{4}{|c|}{ Propriedades } & \multirow[b]{2}{*}{ TOTAL } \\
\hline & 1 & 2 & 3 & 4 & \\
\hline Saanen & 7 & 0 & 0 & 54 & 131 \\
\hline Mestiço Saanen e Boer & 2 & 0 & 0 & 0 & 2 \\
\hline Mestiço Saanen e Boer & 0 & 5 & 0 & 0 & 5 \\
\hline Toggenburg & 0 & 14 & 0 & 0 & 14 \\
\hline Parda Alpina & 0 & 5 & 2 & 0 & 7 \\
\hline SRD & 0 & 0 & 20 & 0 & 20 \\
\hline TOTAL & & & & & 179 \\
\hline
\end{tabular}

O protocolo de lise utilizado demonstrou-se eficiente para extração de DNA . 
Segundo VALDERRAMA et al. (1999) a extração de DNA por meio de bulbos pilosos apresenta as vantagens de simplicidade quanto à coleta e estocagem do material e não oferece risco à sanidade do animal. Desta forma, HOSONO et al. (2003) também defendem a obtenção de DNA por meio de métodos não invasivos.

Ressalta-se a importância da qualidade do material extraído para garantia da sensibilidade e sucesso das técnicas moleculares, uma vez que a escolha indevida do protocolo a ser utilizado pode inviabilizar as amplificações de PCR. Esta etapa da pesquisa representa o início dos estudos genéticos, sendo indispensável uma quantidade de DNA suficiente e de boa qualidade.

Não houve amplificação independente dos iniciadores microssatélites utilizados, bem como, seus diferentes gradientes de temperatura, não sendo observada nenhuma banda nítida nos géis que pudesse ser contabilizada como estimadores da variabiliade genética dos caprinos.

Ao trabalharem com caprinos da raça Anglonubiana no Centro Norte do Piauí, SILVESTRE (2012) obteve amplificação dos mesmos iniciadores que foram trabalhados nesta pesquisa. Este também utilizou amostras de bulbos pilosos, mas sua metodologia de extração foi o uso de $100 \mu \mathrm{L}$ de solução composta por $40 \mathrm{~mL}$ de água Milli-Q e 4g de Chelex-100.

MACIEL (2011) estudando caprinos da raça Gurgueia, também no Piauí, usou alguns dos mesmos iniciadores deste estudo havendo a amplificação dos mesmos. Porém, o autor utilizou amostragem sanguínea e protocolo de extração conforme o fabricante (Whatman Inc. $®$ ), metodologias essas, distintas do referido trabalho.

Ainda na região Nordeste, MENEZES et al. (2006) pesquisaram quanto a variabilidade genética de caprinos das raças Moxotó, Canindé, Serrana Azul, Marota, Repartida e Graúna. Estes utilizaram todos os iniciadores descritos neste estudo e obtiveram amplificações. Apesar de terem utilizado de bulbos pilosos, os autores usaram a metodologia estabelecida por WALSH et al. (1991) para extração do DNA.

Alguns iniciadores utilizados nesta pesquisa são considerados heterólogos aos caprinos, enquanto outros são homólogos a espécie (tabela 4).

TABELA 4. Iniciadores homólogos e heterólogos aos caprinos (FAO, 2004).

\begin{tabular}{ccc}
\hline Iniciadores & Homólogo & Heterólogo \\
\hline CSRD247 & $\mathrm{X}$ & $\mathrm{x}$ \\
ILSTS011 & & $\mathrm{X}$ \\
BM1818 & & $\mathrm{X}$ \\
\hline BM6506 & $\mathrm{X}$ & $\mathrm{X}$ \\
\hline OarFCB304 & & $\mathrm{X}$ \\
\hline MAF65 & & \\
CSSM66 & & \\
SRCRSP8 & & \\
\hline HAUT27 & $\mathrm{X}$ & \\
CSRM60 & $\mathrm{X}$ & \\
BM6526 & $\mathrm{X}$ & \\
McM527 & $\mathrm{X}$ & \\
OarFCB48 & $\mathrm{X}$ & \\
INRA06 & $\mathrm{X}$ & \\
\hline INRA23 & & $\mathrm{X}$
\end{tabular}




\begin{tabular}{ccc} 
INRA63 & & $\mathrm{X}$ \\
\hline HSC & $\mathrm{X}$ & $\mathrm{X}$ \\
\hline ETH225 & & $\mathrm{X}$ \\
ETH10 & & \\
\hline BM1329 & $\mathrm{X}$ & $\mathrm{X}$ \\
\hline OarFCB11 & & $\mathrm{X}$ \\
\hline INRA05 & & $\mathrm{X}$ \\
TGLA122 & & $\mathrm{X}$ \\
SPS115 & & \\
\hline BM8125 & $\mathrm{X}$ & \\
MM12 & $\mathrm{X}$ & $\mathrm{X}$ \\
MAF209 & $\mathrm{X}$ & $\mathrm{X}$ \\
\hline ILSTS05 & & \\
MAF65 & & \\
\hline INRA172 & $\mathrm{X}$ & \\
\hline INRA35 & & $\mathrm{X}$
\end{tabular}

Para os iniciadores homólogos, infere-se que os caprinos amostrados poderiam apresentam uma base genética estreita, havendo a ocorrência de baixo polimorfismo e também não amplificação. De modo geral, os microssatélites são marcadores indicados aos estudos de variabilidade genética dentro da mesma espécie (FOSTER et al., 2010; PESSOA FILHO, 2011). Contudo, SILVA et al. (2011) descrevem que as possíveis amplificações geradas por meio dos marcadores microssatélites entre espécies, quando associadas à natureza do loco, pode garantir a validação dos mesmos como conectores da consolidação de mapas genotípicos com informações fenotípicos de interesse de diferentes espécies.

O uso de iniciadores heterólogos (transferibilidade de marcadores) apresenta as vantagens de redução de custo e tempo das investigações genéticas. Porém, o sucesso desse procedimento depende da estabilidade evolutiva e grau de conservação dos sítios de primers que flanqueiam os loci microssatélites (ZUCCHI et al., 2003). Segundo LORIEUX et al. (2000), quando as espécies são próximas, a chance de partilhar o sítio de ligação dos primers microssatélites é maior do que em espécies distantes, porém, pode também haver tal partilha nas mesmas. Contudo, ao trabalhar com primers heterólogos, segundo GONELA (2003) pode-se esperar uma redução quanto ao número de alelos observados.

O tipo de protocolo utilizado nas extrações de DNA também merece atenção, uma vez que existem diversos métodos dificultando a escolha de um protocolo padrão (MONTEIRO et al., 2014), pois os mesmos devem ainda ser escolhidos conforme as diferenças entre fatores que inibem a amplificação via PCR, presença de contaminantes e densidade microbiana. Para que tais situações sejam evitadas, PESSOA FILHO (2011) e QUIGLEY et al. (2012) aconselham o uso de kits comerciais para extração, pois estes já encontram-se otimizados para tipos específicos de amostras.

Porém, em situações de rotina laboratorial, o uso dos mesmos pode-se tornar inviável devido seu alto custo (MONTEIRO et al., 2014). Ressalta-se também que conforme o protocolo utilizado pode haver a degradação do DNA de outros organismos que causarão a contaminação da amostra (LEVEAU, 2007). A pouca quantidade e a má qualidade do DNA extraído pode representar a causa mais provável da não amplificação pela PCR (MONTEIRO et al., 2014). 
Mesmo que a técnica de PCR seja mais rápida, sensível e confiável que as demais (FRECE et al., 2010), o sucesso de sua reação encontra-se relacionado à concentração dos elementos utilizados, como a do tampão, do cloreto de magnésio $\left(\mathrm{MgCl}_{2}\right)$, dos desoxirribonuleotídeos (dNTP), da quantidade e qualidade de DNA, da Taq, da temperatura de anelamento (MACHADO \& SILVA, 2013) e da quantidade de iniciadores por amostra (SILVA et al., 2014b).

Conforme SELKOE \& TOONEN (2006) deve-se atentar às temperaturas de anelamento, as quais devem ser as mais altas possíveis para a otimização dos iniciadores e redução do tempo de extensão do fragmento. Tais procedimentos podem contribuir para a diminuição do número de bandas inespecíficas e fantasmas, uma vez, que têm-se conhecimento acerca da taxa de incorporação de nucleotídeos pela DNA polimerase (35 - 100 nucleotídeos por segundos em $70-80^{\circ} \mathrm{C}$ para Taq DNA polimerase).

Diante das diferentes hipóteses que podem justificar a não amplificação dos fragmentos, sugere-se que novas alternativas sejam realizadas. Como exemplo, infere-se o uso de diferentes origens de DNA, como o sangue, o sêmen e a saliva. Pode-se ainda, usar outras formas de extração, como os kits comerciais e as estabelecidas por diferentes autores na literatura. Também há a possibilidade do emprego da técnica de Nested-PCR.

Ainda não encontram-se disponíveis na literatura iniciadores específicos para a raça caprina Saanen, sendo esta, uma alternativa a ser desenvolvida. Segundo PORTIS et al. (2007) apenas algumas raças economicamente importantes apresentam microssatélites disponíveis para serem consultados, apesar da raça Saanen ser representativa quanto a produção leiteira caprina no Brasil e no estado do Espírito Santo. Infere-se que isto provém dos altos custos e intensidade de trabalho para seu desenvolvimento, dificultando determinadas situações, como no caso do presente estudo, que careceu de informações a respeito de iniciadores específicos para a raça Saanen.

\section{CONCLUSÃO}

As condições de amplificação dos iniciadores não foram eficientes para o estudo da variabilidade genética dos caprinos da raça Saanen da região sul do estado do Espírito Santo.

\section{REFERÊNCIAS}

ABAD, A. C. A.; LOPES, F. A.; PINHEIRO, J. W.; MOTA, R. A. Marcadores moleculares e suas aplicações nas pesquisas em bovinos. Acta Veterinaria Brasilica, v.8, n.1, p.10-18, 2014.

ARAÚJO, A. M.; GUIMARÃES, S. E.; PEREIRA, C. S.; LOPES, P. S.; RODRIGUES, M. T.; MACHADO, T. M. M. Paternity in Brazilian goats through the use of DNA microsatellites. Revista Brasileira de Zootecnia, v.39, n.5, p.1011-1014, 2010.

BARROS, E. A.; RIBEIRO, M. N.; ALMEIDA, M. J. O.; ARAÚJO, A. M. Estrutura populacional e variabilidade genética da raça caprina Marota. Archivos de Zootecnia, v. 60, n. 231, p. 52, 2011.

BORÉM, A.; CAIXETA, E. T. Marcadores Moleculares. 2. ed. Viçosa: UFV, 532 p. 2009. 
CURI, R. A. Teste de paternidade por microssatélites em bovinos da raça Gir. 2000. 89f. Dissertação (Mestrado em Ciências Biológicas) - Instituto de Biociência, Universidade Estadual Paulista, Botucatu, 2000.

CORRÊA, T. S. Caracterização da diversidade genética de ovinos da região norte do estado do Rio de Janeiro por meio de marcadores microssatélites. 2013. 48f. Dissertação (Mestrado em Ciência Animal) - Universidade Estadual do Norte Fluminense Darcy Ribeiro, 2013.

FAO. Guidelines for Development of National Management of Farm Animal Genetic Resources Plans: Measurement of Domestic Animal Genetic Diversity (MoDAD): Recommended Microsatellite Markers, Rome, Italy, 2004.

FERREIRA, M. E.; GRATTAPAGLIA, D. Introdução ao uso de marcadores moleculares em análise genética. 3. ed. Brasília, DF: Embrapa-Cenargen, 1998. p. 220.

FOSTER, J.T.; ALLAN, G.J.; CHAN, A.P.; RABINOWICZ, P.D.; RAVEL, J.; JACKSON, P.J.; KEIM, P. Single nucleotide polymorphisms for assessing genetic diversity in castor bean (Ricinus communis). BMC Plant Biology, v.10, 2010.

FRECE, J.; MARKOV, K.; CVEK, D.; KOLAREC, K.; DELAS, F. Comparison of conventional and molecular methods for the routine confirmation of Listeria monocytogenes in milk products produced domestically in Croatia. Journal of Dairy Research, v.77, n.1, p.112-116, 2010.

GOLDSTEIN, B. D.; SCHLOTTERER, C. Microsatellites: evolution and applications. Oxford Urdversity Press, New York ; 352 p, 1999.

GONELA, A. Aplicação de marcadores microssatélites de Sus scrofa domestica na caracterização genética de populações de Sus scrofa sp (porco-Monteiro) e Tayassu pecari (queixada). 2003. 89p. Tese (Doutorado em Ciências). Universidade de São Paulo. Ribeirão Preto. São Paulo. 2003.

HEDRICK, P. W. Highly variable loci and their interpretation in evolution and conservation. Evolution, v. 53, p. 313-318, 1999.

HOSONO, S.; FARUQI, A. F.; DEAN, F. B.; DU, Y.; SUN, Z.; WU, X.; DU, J.; KINGSMORE, S. F.; EGHOLM, M.; LASKEN, R. S. Unbiased whole-genome amplification directly from clinical samples. Genome Research, v. 13, p. 954-964, 2003.

IBGE - Instituto Brasileiro de Geografia e Estatística. 2013. Acessado em 07 de Julho de 2015.2 Disponível em:

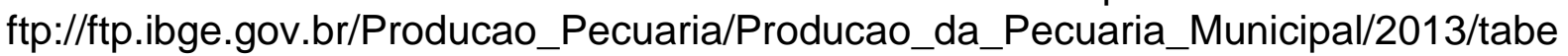
las_pdf/tab18.pdf

KALIA, R. K.; RAI, M. K.; KALIA, S.; SINGH, R.; DHAWAN, A. K. Microsatellite markers: an overview of the recent progress in plants. Euphytica, v. 177, p. 309334, 2011. 
JARNE, P.; LAGODA, P. Microsatellites: from molecules to populations and back. Trends in Ecology and Evolution, v. 11, p. 424-429.1996.

LEVEAU, J. The magic and menace of metagenomics: prospects for the study of plant growth-promoting rhizobacteria. European Journal of Plant Pathology, v. 119 , n. 3, p. 279-300, 2007.

LOPES, D. D. Variabilidade genética, estrutura populacional e relações evolutivas de cabras crespas com base em marcadores moleculares microssatélites e DNA mitocondrial. 2012. 81f. Dissertação (Mestrado em Genética e Biologia Molecular) - Universidade Federal do Rio Grande do Sul, 2012.

LOPES, F. B.; SILVA, M. C.; MIYAGI, E. S.; BORJAS, A. R.; FIORVANTI, M. C. S.; FACÓ, O.; GUIMARAES, R. F.; CARVALHO JÚNIOR, O. A.; MCMANUS, C. Spatialization of climate, physical and socioeconomic factors that affect the dairy goat production in Brazil and their impact on animal breeding decisions. Pesquisa Veterinária Brasileira, v. 11, p. 1073-1081, 2012.

LORIEUX, M.; NDJIONDJOP, M-N; GHESQUIÈRE, A. A first interespecific Oryza sativa \& Oryza glaberrima microsatellite-based genetic linkage map. Theoretical and Applied Genetics, v. 100, p. 593-601, 2000.

MACHADO, E. F.; SILVA, S. A. Desenho e validação de iniciadores microssatélites SSR para mamoneira. Pesquisa Agropecuária Brasileira, v.48, n.11, p.1457-1463, 2013.

MACIEL, S. V. P. A. Caracterização genética de caprinos Gurgueia no Estado do Piauí. 2011. 49f. Dissertação (Mestrado em Genética e Melhoramento) Universidade Federal do Piauí, 2011.

MADELLA-OLIVEIRA, A. F.; QUIRINO, C. R. Caracterização do rebanho de cabras semisselvagens das montanhas do Sul do Espirito Santo, Brasil. Actas Iberoamericanas de Conservación Animal, v. 2, p. 319-322, 2012.

MAPA - Ministério da Agricultura, Pecuária e Abastecimento, 2014. Disponível em: http://www.agricultura.gov.br/animal/especies/caprinos-e-ovinos. Acessado em $10 \mathrm{de}$ junho de 2015.

MENEZES, M. P. C.; MARTINEZ, A. M.; RIBEIRO, M. N.; PIMENTA FILHO, E. C.; BERMEJO, J. V. D. Caracterização genética de raças caprinas nativas brasileiras utilizando-se 27 marcadores microssatélites. Revista Brasileira de Zootecnia, v. 35, n. 4, p. 1336-1341, 2006.

MONTEIRO, F. C.; MONTANHAINI, M. T. M.; NITTENCOURT, J. V. M. Avaliação de protocolos de extração de DNA genômico na verificação da presença de Listeria monocytogenes por PCR. Revista Brasileira de Higiene e Sanidade Animal, v. 08, n. 4, p. 141-156, 2014. 
PESSOA FILHO, M. A. C. P. Metagenômica: princípios e aplicações. In: FALEIRO, F. G.; ANDRADE, S. R. M.; REIS JÚNIOR, F. B. Biotecnologia: estado da arte e aplicações na agropecuária. Planaltina, DF, Embrapa-Cerrados, p. 15-730. 2011.

PORTIS, E.; NAGY, I.; SASVI, Z.; STAGEL, A.; BARCHI, L.; LANTERI, S. The design of Capsicum spp. SSR assays via analysis of in silico DNA sequence, and their potential utility for genetic mapping. Plant Science, v. 172, p. 640-648, 2007.

QUIGLEY, L.; O'SULLIVAN, O.; BERESFORD, T.P.; ROSS, R.P.; FITZGERALD, G.F.; COTTER, P.D. A comparasion of methods used to extract bacterial DNA from raw milk and raw milk cheese. Journal of Applied Microbiology, v.113, n.1, p.96106, 2012.

SANT'ANA, G. C.; FERREIRA, J. L.; ROCHA, H. S.; BORÉM, A.; PASQUAL, M.; CANCADO, G. M. A. Comparison of a retrotransposon-based marker with microsat ellite markers for discriminating accessions of Vitis vinifera. Genetics and Molecular Research, v. 11, p. 1507-1525, 2012.

SELKOE, K. A.; TOONEN, R. J. Microsatellites for ecologists: a practical guide to using and evaluating microsatellite marker. Molecular Letters, v. 9, p. 615-629, 2006.

SILVA, S. A.; PENTEADO, P. R.; PAZZA, R.; KAVALCO, K. F. Avaliação da transferibilidade de lócus de microssatélites em oito espécies de Astyanax. Evolução e Conservação da Biodiversidade, v. 2, n. 1, p. 104-109, 2011.

SILVA, E. C.; MCMANUS, C. M.; GUIMARÃES, M. P. L. M. P.; GOUVEIA, A. M. G.; FACÓ, O.; PIMENTEL, D. M.; CAETANO, A. R.; PAIVA, S. R. Validation of a microsatellite panel for parentage testing of locally adapted and commercial goats in Brazil. Genetics and Molecular Biology, v. 37, n. 1, p. 54-60, $2014 \mathrm{a}$.

SILVA, I. C.; OLIVEIRA, M. S. P.; FORTES, A. C. R. Seleção de primers ISSR para análises genéticas em Tucumã-do-Pará (Astrocaryum vulgare MART.). In: 18은 Seminário de Iniciação Científica e $2^{\circ}$ Seminário de pós-graduação da Embrapa Amazônia Oriental. Anais... Belém - Pará, 2014b.

SILVESTRE, E. A. Caracterização genética de caprinos da raça Anglonubiana no centro norte do Piauí. 2012. 53f. Dissertação (Mestrado em Genética e Melhoramento) - Universidade Federal do Piauí, 2012.

SILVESTRE, E. A.; COSTA, M. S.; SILVA, P. O.; BAJAY, M. M.; PINHEIRO, J. B.; ZUCCHI, M. I.; CAMPELO, J. E. G.; BRITTO, F. B. A note on the distribution of genetic diversity of Anglo-Nubian goats in central-northern farms of Piauí, Brazil. Revista Brasileira de Zootecnia, v. 44, n. 4, p. 155-160, 2015.

SOUZA, E. S.; FALCÃO, D. R. A.; LEAL, S. R.; CORRÊA, T. S.; QUIRINO, C. R. Métodos para coleta e armazenamento de pelos em ovinos (Ovis aries), visando a 
obtenção de DNA. In: 10aㅡ Conferência Sul-americana de Medicina Veterinária. Anais... Rio de Janeiro, 2010.

TEIXEIRA, F. F. Mapeamento de QTLs para caracteres do feijoeiro por meio de microssatélites. 2014. 189p. Tese (Doutorado em Genética e Melhoramento de Plantas) - Universidade Federal de Lavras, 2014.

VALDERRAMA, X.; KARESH, W.B.; WILDMAN, D.E.; MELNICK, D.J. Noninvasive methods for collecting fresh hair tissue, Molecular Ecology, v.8, p1749-1752,1999.

VIANNA, L. S. Caracterização da diversidade genética de duas populações naturais de Vochysia bifalcata warm no Parque Nacional do Caparaó/ES. Nucleus, v. 12, n. 1, p. 173-180, 2015.

WALSH, P.S.; METZGER, D.A.; HIGUCHI, R. Chelex 100 as a medium for a simple extraction of DNA for PCR-based typins from forensic material. Biotecchniques, v.10, p.506-513, 1991.

ZUCCHI, M. I.; BRONDANI, R. P. V.; PINHEIRO, J. B.; CHAVES, L. J.; COELHO, A. S. G.; VENCOVSKY, R. Genetic strutures and gene flow in Eugenia dysenterica DC in the Brazilian Cerrado utilizing SSR markers. Genetics and Molecular Biology, v. 26, p. 449-457, 2003. 